\title{
FRASEO(TOPÔNIMOS): UM ESTUDO DE TOPÔNIMOS POLILEXICAIS NA PERSPECTIVA DA FRASEOLOGIA
}

\author{
PHRA(SETOPONYMS): A STUDY OF POLYLEXICAL \\ TOPONYMS FROM THE PERSPECTIVE OF PHRASEOLOGY
}

\author{
Camila André do Nascimento da SILVA ${ }^{1}$ \\ Aparecida Negri ISQUERDO²
}

\begin{abstract}
Resumo: Este artigo discute resultados de estudo sobre topônimos polilexicais na perspectiva da Fraseologia e possíveis interfaces com a Toponímia. Para tanto, examina uma amostra de dados do corpus do Projeto ATEMS - Atlas Toponímico do Estado de Mato Grosso do Sul, relativos a topônimos que nomeiam acidentes humanos da Microrregião de Paranaíba, com o objetivo de analisar a estrutura morfológica dos designativos, considerando as tendências da composição fraseológica. O estudo pauta-se em fundamentos da Fraseologia (MEJRI, 1997, 2004, 2006) e da Toponímia (DICK, 1990, 1992), incluindo a categoria dos fraseotopônimos como unidades toponímicas grafadas em uma sequência de duas ou mais unidades lexicais que correspondem a um único referente (MARQUES, 2017). O recorte analisado evidenciou a presença de um número representativo de topônimos compostos que se configuram como sequências polilexicais cristalizadas (1.243), com destaque para as compostas de adjetivo + antropônimo (172). Em síntese, os dados apontam para a possibilidade de estudos dos topônimos compostos também na perspectiva da Fraseologia, a par das abordagens tradicionais calcadas nos fundamentos teóricos da Toponímia. Trata-se do exame de um universo de topônimos que, na perspectiva adotada neste estudo, podem ser classificados como fraseotopônimos.
\end{abstract}

Palavras-chave: Fraseotopônimos. Fraseologia. Toponímia. ATEMS.

\begin{abstract}
This article discusses the study results on polylexical toponyms from the perspective of Phraseology and possible interfaces with the Toponymy. For the analysis, is examined a sample of data from the corpus of the Toponymic Atlas Project of Mato Grosso do Sul (ATEMS), related to toponyms that name human accident in the Microregion of Paranaíba, with the objective of analyzing the morphological structure of the designative, considering the trends of the phraseological composition. This study is based on fundamentals of Phraseology (MEJRI, 1997, 2004, 2006) and Toponymy (DICK, 1990, 1992), including the category of phrasetoponyms as toponymic unit written in a sequence of two or more lexical units that correspond to a single referent (MARQUES, 2017). The analyzed data evidenced the presence of a representative number of compound toponyms that are configured as crystallized polylexical sequences $(1,243)$, with an emphasis on those formed by adjective + anthroponymous (172). In summary, the data point to the possibility of toponymic studies of the compound toponyms also in the perspective of Phraseology, along with the traditional approaches based on the theoretical foundations of Toponymy. This is the examination of a universe of toponyms that, in the perspective adopted in this study, can be classified as phrasetoponyms.
\end{abstract}

Keywords: Phrasetoponyms. Phraseology. Toponymy. ATEMS.

1 Universidade Federal do Mato Grosso do Sul (UFMS), Três Lagoas, Mato Grosso do Sul, Brasil;
camilandreufms@hotmail.com; https://orcid.org/0000-0002-3379-1422

2 Universidade Federal do Mato Grosso do Sul (UFMS), Campo Grande, Mato Grosso do Sul, Brasil; aparecida.isquerdo@gmail.com; https://orcid.org/0000-0003-1129-5775 
- | Fraseo(topônimos): um estudo de topônimos polilexicais na perspectiva da fraseologia

\section{Introdução}

A língua, em sua organização e funcionamento, se reestrutura a partir do uso e dessa forma ultrapassa a condição de código, ganha a definição de sistema de representação e permite o reconhecimento do mundo e de seu universo cultural. De modo geral, a língua é resultado de relações e as reflete por meio dos usos que as pessoas dela fazem. Pode-se dizer que o homem encontrou por meio da língua uma forma de materializar seus pensamentos e de representar o mundo em que vive. À maneira de Dubois (1973, p. 378), "no sentido mais corrente, língua é um instrumento de comunicação, um sistema de signos vocais específicos aos membros de uma mesma comunidade".

Particularmente, o léxico traduz a relação entre língua e sociedade, língua e ambiente e língua e cultura, independente da natureza da unidade lexical. As "frases feitas", os provérbios, por exemplo, objeto de estudo da Fraseologia, traduzem a visão de mundo em voga na sociedade de diferentes épocas. Assim, a par da Lexicologia, área de conhecimento que se ocupa do estudo científico do léxico; da Lexicografia que tem como escopo o tratamento lexicográfico do acervo vocabular de uma língua e da Terminologia que se ocupa do estudo do termo em campos distintos de especialidade, a Fraseologia tem se solidificado como a área dos estudos lexicais que fornece parâmetros para o estudo das unidades complexas da língua. Ortíz Alvarez (2000, p. 75), na tentativa de elucidar o conceito de fraseologia, pondera que "na teoria da lexicologia, a fraseologia tem como objeto de estudo a análise de combinações de palavras que formam unidades lexicais ou que têm o caráter de expressões fixas" e acrescenta "que os fraseologismos constituem uma unidade funcional que forma parte do sistema da língua e apresentam uma estrutura complexa, composta por dois ou mais lexemas" (p. 139). Nessa perspectiva, pode-se considerar as construções fraseológicas como uma parcela do léxico notadamente influenciada pelas forças sociais e culturais, o que lhes confere o estatuto de patrimônio da língua, à medida que carrega traços culturais, sociais e históricos de uma determinada comunidade linguística situada em um espaço geográfico determinado.

Ainda no nível lexical da língua situam-se os nomes próprios que gozam de estatuto próprio e são objeto de estudo da Onomástica, área de investigação que tem como subáreas particularmente solidificadas a Antroponímia (estudo dos nomes próprios de pessoas - antropônimos) e a Toponímia (estudo dos nomes próprios de lugares - topônimos) (DICK, 1992, p. 16). A mesma toponimista assim caracteriza o signo toponímico: 
[...], ainda que, na língua, o signo participe, genericamente, de uma natureza convencional de significação, ao se aplicar o mesmo princípio à Toponímia notar-se-á uma diversidade de aspecto: o elemento linguístico comum, revestido, aqui, de função onomástica ou identificadora de lugares, integra um processo relacionante de motivação onde, muitas vezes, se torna possível deduzir conexões hábeis entre o nome propriamente dito e a área por ele designada. (DICK, 1990, p. 34).

Nesse sentido, o signo toponímico, a despeito da sua natureza essencialmente linguística como signo de língua, possui também estreita relação com fatores exteriores à língua como a história social e a geografia do espaço nomeado. Assim em face dessas características inerentes ao topônimo, o seu estudo tem caráter interdisciplinar, razão pela qual pode contribuir para a reconstituição de aspectos relacionados à história de grupos humanos que habitam e/ou habitaram o espaço nomeado e, consequentemente, para o resgate da memória coletiva de um grupo social, evidenciando traços linguísticos e histórico-culturais dos nomes, ao mesmo tempo em que pode evidenciar as causas denominativas que levaram o nomeador a batizar um lugar com determinado nome.

Dentre as áreas que se ocupam do estudo do léxico, como já assinalado, situamse a Fraseologia e a Toponímia, ambas tomadas como referencial teórico para este estudo que discute possíveis interfaces entre essas áreas do saber, partindo do princípio de que esse diálogo justifica-se pelo fato de muitos nomes de lugares evidenciarem características fraseológicas, o que motivou e sustentou a proposição da categoria dos fraseotopônimos apresentada por Marques (2017), com base em estudo de topônimos compostos na perspectiva da Fraseologia. Assim, este estudo propõe-se a interpretar o que se está denominando de realidade fraseotoponímica na nomeação de acidentes humanos rurais (fazendas, sítios, estâncias, chácaras...) pertencentes à Microrregião de Paranaíba, Mesorregião Leste do Estado de Mato Grosso do Sul, a partir de um corpus formado por topônimos compostos.

Em síntese, este estudo toma como ponto de partida a noção de fraseotopônimos proposta por Marques (2017), a partir do diálogo estabelecido pela autora entre Toponímia e Fraseologia, e examina, também com base em teorias sobre Fraseologia (GROSS, 1996; MEJRI, 1997, 2004, 2005, 2006; CORPAS PASTOR, 1996) e em fundamentos teóricos acerca da Toponímia (DAUZAT, 1946, 1947; DICK, 1990, 1992), topônimos armazenados no Sistema de Dados do Projeto ATEMS - Atlas Toponímico do Estado de Mato Grosso do 
- | Fraseo(topônimos): um estudo de topônimos polilexicais na perspectiva da fraseologia

$\mathrm{Sul}^{3}$, na perspectiva da Fraseologia. Ao discorrer sobre a categoria dos fraseotopônimos, Marques (2017) desenvolve o argumento de que o fraseotopônimo é uma "unidade toponímica que, no plano da escrita, é grafada como uma sequência de duas ou mais unidades lexicais que correspondem a um único referente: o acidente geográfico físico ou humano que ele nomeia" (MARQUES, 2017, p. 25). Neste trabalho, busca-se, sobretudo, analisar a estrutura morfológica dos designativos selecionados segundo as tendências da composição fraseológica, ou seja, examinando a questão da presença de sequências polilexicais cristalizadas ${ }^{4}$ na estrutura dos topônimos compostos estudados.

A estrutura do artigo contempla as seguintes seções: discussão teórica de pressupostos da Fraseologia e da Toponímia; questões metodológicas que orientaram o estudo e análise dos fraseotopônimos identificados na amostra do corpus examinada.

\section{Pressupostos teóricos}

\subsection{Conceituando a Fraseologia}

Em 1931, surgiram as primeiras definições de uma nova disciplina, a Fraseologia, concebida como "uma disciplina especial da área da linguagem que ocupa, em relação ao léxico, a mesma posição que a sintaxe desempenha em relação à morfologia", ou seja, como um ramo de conhecimento linguístico cujo objeto de estudo são as expressões fixas e seus significados, aos quais se denominam fraseologismos (POLIVÁNOV, 1931 apud ORTíZ ALVAREZ, 2000, p. 705). A partir de 1940, estudiosos começaram a considerar que, por intermédio das construções fraseológicas, tanto a língua, quanto a forma de pensar de um povo poderiam ser reveladas. Ortíz Alvarez (2000, p. 71) esclarece que, na década de 1940, "a fraseologia se inscreve como disciplina lingüística, sendo a época do maior desenvolvimento das pesquisas dos lingüistas russos nessa área destacando-se Vinogradov (1938) que foi o primeiro a classificar sincrónicamente as unidades fraseológicas do ponto de vista funcional".

3 O ATEMS - Atlas Toponímico do Estado de Mato Grosso do Sul - é um projeto em desenvolvimento na Universidade Federal de Mato Grosso do Sul que se orienta fundamentalmente pelo modelo teóricometodológico concebido por Dick $(1990,1992)$. O Projeto ATEMS tem como objetivo mais amplo catalogar e analisar a toponímia rural e urbana dos 79 municípios do Estado de Mato Grosso do Sul/Brasil.

4 Este estudo apoia-se em Mejri (2004, p. 14, tradução nossa) para explicar o termo polilexical: "[...] significa plural (= poli), formado por várias unidades lexicais utilizadas de forma autônoma fora do quadro da sequência (= léxico)"; no original: "[...] signifiant pluriel (= poly), formé de plusieurs unités lexicales employées d'une manière autonome hors du cadre de la séquence (= lexical)".

5 É preciso pontuar aqui que Saussure foi um dos primeiros linguistas a teorizar sobre a questão das combinações fixas de palavras na língua que foi concebida por ele como um sistema: "um grande número de expressões que pertencem à língua; são as frases feitas, nas quais o uso proíbe qualquer modificação, mesmo quando seja possível distinguir, pela reflexão, as partes significativas" (SAUSSURE, 2012, p. 173). 
Mejri (1997), por sua vez, define os fraseologismos como um fenômeno que se exprime por meio de associações sintagmáticas recorrentes e aponta a fixação (figement) como o processo pelo qual essas associações se realizam. Segundo o entendimento desse autor, as unidades fraseológicas são nomeadas como sequências fixas (sequence figée). Desse modo, as unidades sintagmáticas livres tornam-se unidades sintagmáticas fixas, ou seja, o processo de fixação é a operação pela qual as associações sintagmáticas se concretizam.

Ortíz Alvarez (2000, p. 72) alerta também para o fato de que, "se examinarmos a sistematicidade das unidades fraseológicas, teremos de analisar os seus traços semânticos e estruturais, isto é, os traços que caracterizam o princípio de organização das unidades fraseológicas e do seu significado". Por essa razão, o problema da sistematicidade está vinculado à definição dos tipos de unidades fraseológicas.

Desta forma, nesse panorama, pode-se considerar o fraseologismo ${ }^{6}$ como uma formação lexical que possui uma escala de fixação que varia do menor grau (colocações) ao maior grau (grande parte das expressões idiomáticas e os provérbios), sujeita às normas de um idioma ${ }^{7}$. Do mesmo modo que o emprego apropriado das palavras em uma combinatória livre, o uso de uma expressão fixa é definido pela idiomaticidade da língua a que pertence, razão pela qual configura-se ao mesmo tempo como um segmento linguístico idiomático, cultural e estilístico.

\subsection{Conceituando a Toponímia}

Como anteriormente assinalado, a Onomástica tem como objeto de estudo os nomes próprios de lugares e de pessoas. A subárea da Onomástica aqui tomada como um dos referenciais teóricos, a Toponímia, tem seus primórdios na França, por volta de 1878, com os estudos de Auguste Longnon e foi consolidada por Albert Dauzat por volta de 1926, linguista que impulsionou os estudos sobre Toponímia na França, inspirando-se para tanto em princípios da Geografia Linguística. No Brasil, os estudos toponímicos têm

6 “Fraseologismo é utilizado como termo amplo, como o hiperônimo que recobre uma variada tipologia de unidades léxicas complexas, provérbios e fórmulas de rotina. Há uma profusão terminológica para designar o fenômeno fraseológico, porém, optamos por fraseologismo por acreditarmos que o termo é mais coerente com o nome da área de investigação que estuda esse fenômeno da linguagem humana" (MARQUES, 2017, p. 25).

7 As expressões fixas podem evidenciar uma fixidez completa ou parcial e trazem consigo uma evolução de fixação. Etapas dessa evolução, no processo de fixação, são destacadas em Mejri (1997). 
- | Fraseo(topônimos): um estudo de topônimos polilexicais na perspectiva da fraseologia

como primeiros representantes Theodoro Sampaio (1901), Levy Cardoso (1961) e Carlos Drumond (1965). No entanto, é a Tese de Dick defendida em 1980 na Universidade de São Paulo $^{8}$ que deu impulso a essa área de pesquisa no Brasil ${ }^{9}$.

Para Dick (1990, p. 21), a Toponímia distingue "os acidentes geográficos na medida em que delimitam uma área da superfície terrestre e lhes conferem características específicas". Os topônimos, por sua vez, se apresentam como:

[...] verdadeiros "testemunhos históricos" de fatos e ocorrências registrados nos mais diversos momentos da vida de uma população, encerram, em si, um valor que transcende ao próprio ato da nomeação: se a Toponímia situa-se como a crônica de um povo, gravando o presente para o conhecimento das gerações futuras, o topônimo é o instrumento dessa projeção temporal. (DICK, 1990, p. 22).

De acordo com Dick (1992), os topônimos são signos carregados de significados, por isso a pesquisa toponímica possibilita ao estudioso o resgate linguístico, histórico e social do nome, uma vez que o topônimo marca o fato social e, mesmo que desaparecido, ficará marcado na toponímia e permitirá um resgate de memória. Em outras palavras, "o topônimo 'corporifica' uma soma de fatores linguísticos, étnicos, socioculturais, históricos e ideológicos de um grupo que vive em um determinado espaço geográfico" (DICK, 1992, p. 35-36).

Portanto, é possível afirmar que o léxico toponímico, não raras vezes, é arraigado às tradições e costumes de um povo e os topônimos incorporam traços ideológicos da sociedade em diferentes momentos da sua história ${ }^{10}$.

\footnotetext{
8 A tese de Dick denominada A motivação toponímica. Princípios teóricos e modelos taxionômicos (1980) foi publicada em 1990 com o título A motivação toponímica e a realidade brasileira. Para este estudo, foi consultada a versão publicada.

9 A respeito das fases dos estudos toponímicos no Brasil, confira Isquerdo (2012).

10 Cf. a esse respeito "Os nomes como marcadores ideológicos" (DICK, 1998, p. 97-122).
} 


\subsection{Em busca do conceito de fraseotopônimon ${ }^{11}$}

A discussão do conceito de fraseotopônimos no âmbito deste estudo toma como parâmetro a posição de Marques (2017), de que certos topônimos apresentam propriedades similares às das unidades fraseológicas. Segundo a autora:

Ainda que de forma preliminar, a definição de fraseotopônimo aponta para uma unidade toponímica que, no plano da escrita, é grafada como uma sequência de duas ou mais unidades lexicais que correspondem a um único referente: o acidente geográfico físico ou humano que ele nomeia. (MARQUES, 2017, p. 25).

Marques (2017, p. 25-26) reitera um dos critérios fundamentais para a definição de fraseologismos, a "polilexicalidade ou multilexicalidade", pontuando que a unidade plurilexical "é a primeira propriedade que salta à vista, por ser ela a característica essencial, inerente ao signo de natureza fraseológica". Com base nesse pressuposto, todo fraseotopônimo é formado por, no mínimo, dois itens lexicais.

Outros teóricos como Tristá Pérez (1984), Corpas Pastor (1996), Santamaría Pérez (2000) e Ortíz Alvarez (2000) concebem os fraseologismos como unidades lexicais cujas estruturas são complexas e compreendem mais de uma unidade lexical. Xatara e Rios (2007, p. 58), no entanto, contrariam essa concepção, argumentando que as unidades fraseológicas podem ser "formas simples ou complexas".

Ao discutir a unidade toponímica composta com características fraseológicas, Marques (2017), pautando-se nas ideias de Gross (1996, p. 154), esclarece que o autor "já alertava para a parcialidade da fixidez ao afirmar que nem toda sequência é totalmente fixa. Existem graus de liberdade que oscilam de um ponto que vai das formas totalmente fixas às formas que sofrem algum tipo de variação" (MARQUES, 2017, p. 26).

Marques (2017) pondera ainda que a fixidez, denominada também de cristalização, ocorre tanto no plano formal quanto no semântico: "no plano formal, a cristalização diz respeito à soldadura entre os itens lexicais que integram a unidade fraseológica ou, neste

\footnotetext{
11 Essa discussão acerca da possível interface entre a Fraseologia e a Toponímia é um dos produtos do estágio de doutorado sanduíche (CAPES/COFECUB) realizado por Camila André do Nascimento da Silva, na Université Paris 13, sob orientação do Prof. Dr. Salah Mejri, com foco nos estudos da toponímia na perspectiva fraseológica, associado a resultados preliminares do projeto de Tese de Doutorado, em curso, na Universidade Federal de Mato Grosso do Sul, Campus de Três Lagoas, sob orientação da Profa. Dra. Aparecida Negri Isquerdo, que tem como objeto de investigação a toponímia indígena de acidentes físicos rurais do Estado de Mato Grosso do Sul.
} 
- | Fraseo(topônimos): um estudo de topônimos polilexicais na perspectiva da fraseologia

caso, o fraseotopônimo", enquanto no plano semântico "cada item lexical que compõe o nome deixa de expressar isoladamente o significado que comporta" (MARQUES, 2017, p. 26).

Ao considerar um topônimo composto como um caso de fraseologismo, buscase, sobretudo, aliar a descrição das unidades fraseológicas à pesquisa toponímica. Para tanto, parte-se da acepção de fraseologismos como estruturas cristalizadas pelo uso da língua e formadas por combinações sintagmáticas que não podem ser improvisadas, ou seja, uma sequência fixa que, nessa perspectiva, toma o topônimo composto como "Um sintagma formado em conformidade com a sintaxe da língua e que, uma vez reutilizado e introduzido no uso, será também uma sequência estática" (MEJRI, 1997, p. 29, tradução nossa $\left.{ }^{12}\right)$.

Entre as onze propriedades que caracterizam as expressões fixas ${ }^{13}$ apontadas por Gross (1996), destacam-se neste estudo a polilexicalidade e a fixidez (em seus diferentes graus $)^{14}$, propriedades que serão discutidas, no tópico 3 deste texto, a partir dos dados do corpus examinado. As expressões fixas são formadas por duas ou mais unidades lexicais autônomas da língua, detentoras de sentido próprio, cujo sentido, em geral, não resulta da soma dos significados de suas unidades simples anteriores. Em outras palavras, a fixidez se dá a partir do momento em que os significados das palavras não podem ser entendidos pela soma dos seus constituintes; o sentido deve ser tomado de modo global e, em muitos casos, constituído por uma combinação lexical metafórica.

Segundo Gross (1996, p. 7, tradução nossa"15), "Palavras poliléxicas (ou palavras complexas), correspondem a qualquer unidade (ou categoria gramatical ou parte de discurso) composta por duas ou mais palavras simples ou derivadas preexistentes".

\footnotetext{
12 No original: "un syntagme formé conformément à la syntaxe de la langue et qui, une fois réutilisé et entré dans l'usage, sera lui aussi une séquence figée".

13 Mejri (1997) utiliza o termo sequência fixa.

14 Conforme as teorias de Gross (1996) e de Mejri (1997), os fraseologismos podem evidenciar diferentes graus de fixidez, pois em cada sequência fixa os itens lexicais podem estar unidos de tal maneira que são imutáveis, indissociáveis, convivendo em uma relação de fixidez total, como em (fazenda) D. Emília e (Estância) D. Pedro II. Em outros casos, pode ocorrer que apenas um elemento é fixo e o outro pode ser trocado, admitindo-se, portanto, a substituição de um item lexical da combinatória e trazendo uma evolução de cristalização ou fixação que pode ser acentuado em exemplos de toponimização: (fazenda) da Fazenda Perdiz e (fazenda) Barra do Córrego do Buritizal.

15 No original: "des mots polylexicaux (ou mots complexes), correspondant à toute unité (ou catégorie grammaticale ou partie de discours) composée de deux ou de plusieurs mots simples ou mots dérivés préexistants".
} 
O autor argumenta ainda que as lexias compostas são consideradas expressões fixas, pois "Um nome composto funciona como um bloco do ponto de vista de suas relações com o resto da frase" (GROSS, 1996, p. 28, tradução nossa ${ }^{16}$ ).

Mejri (2006, p. 214, tradução nossa ${ }^{17}$ ), por sua vez, define a polilexicalidade como "[...] A característica morfológica própria das unidades lexicais formadas por várias unidades lexicais e cujos constituintes são, na origem, unidades autônomas". Observa-se que o autor propõe o conceito de palavra polilexical para classificar formações compostas, pois para ele as locuções também são palavras dessa categoria.

Já Pamies (2018, p. 229, tradução nossa ${ }^{18}$ ) substitui o critério da polylexicalité pelo da polylexématicité e defende que "A composição implica sempre (pelo menos) dois lexemas, limiar mínimo necessário para que entre eles se produza a fixidez e, eventualmente, a idiomaticidade". O autor também discute o conceito de synthème, termo definido por Martinet (1999, p. 11-13, tradução nossa ${ }^{19}$ ) como "Uma sequência formada por elementos que podem ser reconhecidos semanticamente porque existem também como monemas autônomos (fer-à-repasser), mas formando um bloco que se combina como um monema único, seria a unidade fraseológica menor". Para o mesmo autor, os exemplos citados por Martinet incluem "O que os fraseólogos chamam hoje em dia locuções verbais (avoir l'air), locuções adjetivais (bon marché), palavras compostas (bon-homme, machine-à-laver) e fraseotermos ${ }^{20}$ (Ministre du Commerce)" (PAMIES, 2018, p. 229-230, tradução nossa ${ }^{21}$ ).

\footnotetext{
16 No original: "un nom composé fonctionne comme un seul bloc du point de vue de ses relations avec le rest de la frase"

17 No original: "la caractéristique morphologique propre aux unités lexicales formées de plusieurs unités lexicales et dont les constituants sont, à l'origine, des unités autonomes".

18 No original: "la composition implique toujours (au moins) deux lexémes, seuil minimum nécessaire pour qu'entre eux se produisent le figement et, éventuellement, l'idiomaticité".

19 No original: "une séquence formée par des éléments qui peuvent être reconnus sémantiquement parce qu'ils existent aussi comme monèmes autonomes (fer-à-repasser) mais formant un bloc qui se combine comme un monème unique, serait l'unité phraséologique la plus petit".

20 Phraséotermes são unidades fraseológicas especializadas com diferentes graus de fixação, ou seja, são combinações polilexicais terminológicas.

21 No original: "ce que les phraséologues appellent de nos jours locutions verbales (avoir l'air), locutions adjectivales (bon marché), mots composés (bon-homme, machine-à-laver) et phraséotermes".
} 
- Fraseo(topônimos): um estudo de topônimos polilexicais na perspectiva da fraseologia

A priori, Pamies (2018, p. 229, tradução nossa ${ }^{22}$ ) assim justifica o uso do termo Synthème, cunhado por Martinet (1999):

Preferimos, portanto, para não depender do conceito de palavra, falar de polylexématicité presente em todas as synthèmen ("vários lexemas funcionando como um só"), mesmo que tenhamos de incluir sequências como casse-croûte ou étoile de mer entre as unidades fraseológicas, a fim de preservar a própria definição de fixidez.

Ainda segundo Pamies (2018, p. 230, tradução nossa $\left.{ }^{23}\right)$, a categoria synthème seria um ponto comum entre diferentes subclasses fraseológicas, como ocorre em: "(fr.) lanterne rouge (locução nominal), voir rouge (locução verbal), rouge-gorge (nome composto), Mer Rouge (construção ônimica) e globule rouge (phraséoterme), todos bimembres e contendo o adjetivo vermelho". O autor assinala que a abordagem léxico-gramatical inclui os compostos na mesma categoria que as locuções, ou seja, na categoria dos synthème, com o diferencial de que as locuções se dividem em diferentes tipos, como locução adverbial, adjetival ou verbal (PAMIES, 2018, p. 230). Pamies (2014, p. 57) ainda relaciona o conceito de synthème com o fenômeno fraseológico:

Martinet já estava identificando a base do fenômeno fraseológico ao definir o sintema. Mas, posto que se trata de uma sequência fixa de vários lexemas que funcionam sintaticamente como um só, há uma categoria linguística funcionando como metáfora de outra categoria, ou seja, uma projeção metafórica entre níveis morfológicos diferentes.

Segundo Pamies (2014, p. 65), "ninguém duvida do caráter gradual da fixação [...], assinalados desde o início da teoria fraseológica, mas a existência de zonas intermédias e até de um continuum no objeto estudado não anula as vantagens metodológicas de usar categorias metalinguísticas discretas para a sua análise", ou seja, a classificação apresentada pelo autor tenta aproveitar as vantagens sem questionar a gradualidade dos critérios tradicionais.

22 No original: “Nous préférons donc, pours ne pas dépendre du concept de mot, parler de polylexématicité présente dans tout synthèmen (" plusieurs lexèmes fonctionnant comme um seul»), quitte à devoir inclure des séquences comme casse-croûte ou étoile de mer parmi les unités phraséologiques, afin de préserver la définition même du figement".

23 No original: "(fr.) lanterne rouge (locution nominale), voir rouge (locution verbale), rouge-gorge (nom composé), Mer Rouge (construction onymique) et globule rouge (phraséoterme), toutes bimembres et contenant l'adjectif rouge". 
Retomando Gross (1996), para classificar uma sequência como fixa, neste estudo foram utilizadas como parâmetro as etapas de fixidez propostas pelo próprio autor, para quem o conceito de fixidez permite, sobretudo, informar fenômenos de natureza muito diversa. De acordo com Gross (1996, p. 9, tradução nossa ${ }^{24}$ ): “[...] O termo mais apropriado é o de estagnação, pois permite dar conta simultaneamente de fenômenos de natureza muito diversa, mas que não são independentes uns dos outros", em geral, interpretado pelos falantes com seu significado idiomático, e não pela soma dos sentidos literais das palavras que as compõem.

No âmbito deste estudo, o levantamento de dados demonstrou um número significativo de topônimos compostos passíveis de atestar a tese dos fraseotopônimos. Os exemplos, a seguir, mostram que a segmentação de topônimos dessa natureza é impossível, confirmando, assim, a hipótese de esses topônimos configurarem-se como fraseologismos.

Quadro 1. Amostra de topônimos candidatos a fraseotopônimos

\begin{tabular}{|l|l|l|l|}
\hline $\begin{array}{l}\text { Elemento } \\
\text { Geográfico }\end{array}$ & $\begin{array}{l}\text { Elemento Específico } \\
\text { Fraseo(topônimo) }\end{array}$ & Taxionomia & Estrutura Morfológica \\
\hline Sítio & Ilha dos Sonhos & Geomorfotopônimo & $\begin{array}{l}\text { Substantivo + Preposição + } \\
\text { Substantivo }\end{array}$ \\
\hline Fazenda & Chão de Estrelas & Litotopônimo & $\begin{array}{l}\text { Substantivo + Preposição + } \\
\text { Substantivo }\end{array}$ \\
\hline Fazenda & Lago Azul & Hidrotopônimo & Substantivo + Adjetivo \\
\hline Fazenda & Lapa do Lobo & Litotopônimo & $\begin{array}{l}\text { Substantivo + Preposição + } \\
\text { Substantivo }\end{array}$ \\
\hline Fazenda & Estrela da Pontinha & Astrotopônimo & $\begin{array}{l}\text { Substantivo + Preposição + } \\
\text { Substantivo }\end{array}$ \\
\hline Fazenda & Onça de José Lata & Zootopônimo & $\begin{array}{l}\text { Substantivo + Preposição + } \\
\text { Antropônimo }\end{array}$ \\
\hline Fazenda & $\begin{array}{l}\text { Ariranha de Agenor } \\
\text { F. de Oliveira }\end{array}$ & Zootopônimo & $\begin{array}{l}\text { Substantivo + Preposição + } \\
\text { Antropônimo }\end{array}$ \\
\hline Fazenda & $\begin{array}{l}\text { Árvore Grande de } \\
\text { Andrelino Arantes }\end{array}$ & Fitotopônimo & $\begin{array}{l}\text { Substantivo + Adjetivo + Preposição } \\
+ \text { Antropônimo }\end{array}$ \\
\hline Estância & D. Pedro II & Axiotopônimo & $\begin{array}{l}\text { Substantivo + Antropônimo + } \\
\text { Numeral }\end{array}$ \\
\hline Fazenda & Espicha Couro II & Sociotopônimo & Verbo + Substantivo + Numeral \\
\hline
\end{tabular}

Fonte: Elaboração própria

24 No original: "le terme de plus approprié est celui de figement, car il permet de rendre compte à la fois de phénomènes de nature très diverse mais qui ne sont pas indépendants les uns des autres". 
- | Fraseo(topônimos): um estudo de topônimos polilexicais na perspectiva da fraseologia

(1) Ilha dos Sonhos; Chão de Estrelas; Lago Azul; Lapa do Lobo e Estrela da Pontinha são fraseotopônimos que apresentam fixidez completa, isto é, o significado global do topônimo não sofre variação. Além disso, o topônimo recupera o sentido original das palavras que os forma a partir da analogia estabelecida entre as características dos referentes que nomeiam e o lugar que é batizado com esse nome. Em outros termos, a fixidez desses topônimos é constituída por uma combinação lexical metafórica e o item lexical que compõe o nome deixa de expressar isoladamente o significado que comporta formando unidades sintagmáticas fixas aqui denominadas fraseotopônimos.

(2) Onça de José Lata; Ariranha de Agenor F. de Oliveira e Árvore Grande de Andrelino Arantes mostram, também, um grau de fixidez, porém o sentido deduzido a partir dos elementos que compõem o designativo alerta para a parcialidade dessa fixidez, ratificando, assim, que nem toda sequência é totalmente fixa. Esses exemplos confirmam o grau de liberdade que oscila entre uma sequência totalmente fixa e as que sofrem algum tipo de variação. O denominador pode estabelecer o sentido exato do topônimo, mas também é possível recuperar o sentido, pelo contexto, mesmo que de forma fragmentada, evidenciando que o processo de fixação é a operação pela qual as associações sintagmáticas se concretizam.

(3) D. Pedro // também se situa entre fraseotopônimos em que se observa um grau de fixidez completo, por recuperar a figura histórica "Dom Pedro de Alcântara", também conhecido como o imperador Dom Pedro Il e ter a sua significação explicada por meio do contexto histórico brasileiro. Cabe aqui destacar que todos os axiotopônimos (topônimos compostos em que o primeiro formante indica títulos - dom, comandante, general, frei... - que é seguido por um nome próprio) podem ser tomados como fraseotopônimos, por apresentarem um grau de fixidez absoluto, pois se configuram como formações cristalizadas por meio de influências do contexto histórico, político e social.

(4) Espicha Couro I/ é também um exemplo de fraseotopônimo com fixidez completa, por reaver o sentido original do sintagma verbal no ato de nomeação e distinguir um novo designativo que corresponde a um único referente, de forma totalmente fixa e estrutura poliléxica.

Os exemplos de topônimos compostos analisados evidenciam seus mecanismos de formação, em especial pela noção de fixidez metafórica, e, sobretudo, pelo conceito de fixidez análoga que acarreta ações próprias de nomeação, evoca esferas particulares de motivação e evidencia a importância da relação entre os estudos fraseológicos e os toponímicos. 
Em síntese, entende-se que a tentativa de estabelecer interfaces entre as disciplinas Fraseologia e Toponímia justifica-se pelo fato de os topônimos compartilharem propriedades fraseológicas e, nesse sentido, julga-se pertinente examinar dados toponímicos a partir de novas perspectivas, pois o lugar de onde se olham os sintagmas toponímicos advém, sobretudo, do caráter fraseológico dessas construções.

\section{Aspectos metodológicos}

Para este estudo, buscou-se respaldo teórico-metodológico na Linguística, mais especificamente na Fraseologia e na Toponímia, para analisar os topônimos compostos como unidades fraseológicas. Essa proposta surge da constatação de que determinados topônimos, à primeira vista, apresentam propriedades bastante similares às dos fraseologismos, por representarem formações lexicais compostas por, no mínimo, duas unidades léxicas inseparáveis no plano formal, gerando, quase sempre, uma unidade de sentido, como ocorre em Fazenda Água Vermelha, uma formação lexical composta por dois itens lexicais indissociáveis no plano formal, gerando, assim, uma única unidade de sentido, fenômeno que motiva a seguinte pergunta: todo topônimo composto pode ser entendido como um fraseotopônimo?

Na busca de respostas para esse questionamento, foram examinados topônimos compostos por dois ou mais itens lexicais, independente da base linguística dos formantes. Em topônimos como (Estância) S. Helena; (Fazenda) Chapada das Flores; (Chácara) José Carlos; (Retiro) Sta. Terezinha; (Sítio) Ilha dos Sonhos, o elemento específico do sintagma toponímico, o topônimo propriamente dito, segundo Dick (1992), no caso de topônimos compostos, é formado por mais de um item léxico e há a fixação dos itens lexicais entre si na configuração do nome do lugar, pois a substituição de um deles desconfiguraria o topônimo, ou seja, o nome próprio que identifica o acidente geográfico nomeado.

O corpus selecionado para este estudo reúne topônimos compostos que nomeiam acidentes humanos localizados nos quatro municípios da Microrregião de Paranaíba, Mesorregião Leste do Estado de Mato Grosso do Sul. No Sistema de Dados do Projeto ATEMS, foram identificados 1.748 topônimos que nomeiam acidentes humanos no espaço geográfico selecionado, dentre os quais 1.243 se configuram como topônimos compostos, constituídos de frases ou enunciados linguísticos e 505 são topônimos simples, formados por um só item lexical, conforme é possível observar na tabela a seguir: 
- | Fraseo(topônimos): um estudo de topônimos polilexicais na perspectiva da fraseologia

Tabela 1. Distribuição dos dados do corpus segundo os municípios da microrregião de Paranaíba/MS

\begin{tabular}{c|c|c|c|c|c}
\hline Municípios & Topônimos & \multicolumn{2}{|c|}{ Topônimos Simples } & \multicolumn{2}{c}{ Topônimos Compostos } \\
\hline $\begin{array}{c}\text { Aparecida do } \\
\text { Taboado }\end{array}$ & 374 & 113 & 22,37 & 261 & $\mathbf{\%}$ \\
\hline Inocência & 453 & 164 & 32,47 & 289 & 23,25 \\
\hline Paranaíba & 814 & 180 & 35,64 & 634 & 51,00 \\
\hline Selvíria & 107 & 48 & 9,52 & 59 & 4,76 \\
\hline Total & $\mathbf{1 . 7 4 8}$ & $\mathbf{5 0 5}$ & $\mathbf{2 8 . 8 9 \%}$ & $\mathbf{1 . 2 4 3}$ & $\mathbf{7 1 . 1 1 \%}$ \\
\hline
\end{tabular}

Fonte: Elaboração própria

Em termos de estrutura, os topônimos, elementos específicos do sintagma toponímico, são classificados segundo a sua formação em: i) elemento específico simples: constituído por um só formante como em (Fazenda) Santana; (Fazenda) Primavera; (Fazenda) Progresso; (Fazenda) Sabiá; (Fazenda) Bacuri; (Fazenda) Irara; (Fazenda) Sapé; (Fazenda) Mactube; ii) elemento específico composto: formado por dois ou mais elementos: (Fazenda) do Formoso do Córrego dos Bois; (Sítio) N. S. Aparecida; (Estância) S. Gerônimo; (Chácara) Santa Rita; (Retiro) Fazenda Córrego da Porteirinha e iii) elemento específico composto híbrido que reúne itens lexicais de diferentes procedências. As formações híbridas de maior frequência na toponímia brasileira são a portuguesa + indígena ou a indígena + portuguesa: (Fazenda) Nova dos Cupins (português + indígena); (Fazenda) Ipê da Serra (indígena + português); (Fazenda) Alto Paraná (português + indígena); (Fazenda) Ariranha de João Rosa (indígena + português + português); (Fazenda) S. José do Córrego Tapera (português + português + indígena); (Fazenda) Santo Antônio do Indaiá (português + português + indígena); (Fazenda) Irara de JoséA. Macedo (indígena + português + português); (Fazenda) S. Luiz do Sucuriú (português + indígena), (Sítio) Tamandaré de Otávio Simões (indígena + português + português +) para citar alguns casos.

Segundo Dick (1990), a estrutura do sintagma toponímico reúne um elemento genérico (relativo à entidade geográfica nomeada) e um elemento específico (topônimo propriamente dito), conforme se vê nos exemplos apresentados no quadro a seguir. 
Quadro 2. Estrutura do Sintagma Toponímico

\begin{tabular}{|l|l|}
\hline \multicolumn{1}{|c|}{ Elemento Genérico } & \multicolumn{1}{c|}{ Elemento Específico Composto } \\
\hline Fazenda & Santo Antônio \\
\hline Fazenda & Nossa Senhora Aparecida \\
\hline Fazenda & São José \\
\hline Fazenda & Bela Vista \\
\hline Fazenda & Santa Maria \\
\hline Fazenda & São Jorge \\
\hline
\end{tabular}

Fonte: Elaboração própria a partir de Dick (1990)

Tendo em vista a dimensão do corpus analisado (Tabela 1) e as normas da revista quanto ao número de páginas, optou-se por trazer como exemplo os elementos específicos compostos mais produtivos no corpus pesquisado (Quadro 2), ou seja: na Microrregião de Paranaíba, existem 28 (21\%) fazendas denominadas de Santo Antônio; 22 (17\%) fazendas nomeadas como Nossa Senhora Aparecida; 22 (17\%) fazendas designadas de São José; 20 (15\%) com o nome de Bela Vista; 20 (15\%) batizadas de São Jorge e 20 (15\%) fazendas chamadas Santa Maria, o que evidencia um maior índice de produtividade de topônimos de cunho religioso, dando mostras da força das crenças religiosas no ato de nomeação e, em uma segunda instância, o nomeador imprime nos nomes sentimentos e sensações associados a aspectos positivos do lugar, que podem estar relacionados à paisagem local ou a sentimentos e expectativas do denominador em relação ao lugar nomeado.

Neste caso, o topônimo composto corresponde ao fraseotopônimo, por ser formado por mais de um item lexical (característica morfológica de polilexicalidade), sobretudo, imutável, indissociável, unido a uma relação que varia em um contínuo de fixidez total e/ ou parcial (em seus diferentes graus) com base na teoria proposta por Gross (1996) e por Mejri (1997), que admite a substituição de um item lexical da combinatória e traz uma evolução de cristalização ou fixação. Na sequência, no item 3, analisam-se e discutem-se outros casos de topônimos candidatos a fraseotopônimos.

\section{Análise e discussão dos topônimos polilexicais}

A análise de estrutura morfológica dos topônimos compostos selecionados aponta para a predominância de designativos formados por duas ou mais unidades lexicais. No total de 1.748 topônimos analisados, 1.243 são de estrutura morfológica composta (71,11\%) e 505 de estrutura simples (28,89\%). Nota-se, pois, que o recorte de topônimos analisados 
- | Fraseo(topônimos): um estudo de topônimos polilexicais na perspectiva da fraseologia

evidenciou um número representativo de sequências polilexicais cristalizadas. Assim, considerando o fato de os topônimos examinados apresentarem propriedades muito similares às dos fraseologismos, ratifica-se a possibilidade de interface entre a Fraseologia e a Toponímia. Descrevem-se, na sequência, uma amostra de exemplos de topônimos compostos e suas estruturas mais recorrentes:

Quadro 3. Estruturas morfológicas dos fraseotopônimos - uma amostra do corpus

\begin{tabular}{|l|c|l|}
\hline \multicolumn{1}{|c|}{ Estrutura Morfológica } & Ocorrências & \multicolumn{1}{c|}{ Exemplos de Fraseotopônimos } \\
\hline Adjetivo + Antropônimo & 172 & (Fazenda) Santa Josefina \\
\hline Substantivo + Adjetivo & 65 & (Fazenda) Pedra Negra \\
\hline $\begin{array}{l}\text { Substantivo + Preposição + } \\
\text { Substantivo }\end{array}$ & 63 & (Fazenda) Vale do Sol \\
\hline Preposição + Antropônimo & 49 & (Fazenda) de Joaquim Bernardes \\
\hline Adjetivo + Substantivo & 36 & (Fazenda) Alto Bacuri \\
\hline Antropônimo & 33 & (Fazenda) Carlito A. Ferreira \\
\hline $\begin{array}{l}\text { Preposição + Substantivo + } \\
\text { Preposição + Substantivo }\end{array}$ & 29 & (Fazenda) do Coqueiro da Estiva \\
\hline $\begin{array}{l}\text { Preposição + Substantivo + } \\
\text { Preposição + Antropônimo }\end{array}$ & 29 & (Fazenda) da Divisa de Elione Paula \\
\hline Numeral + Substantivo & 26 & (Fazenda) Dois irmãos \\
\hline $\begin{array}{l}\text { Substantivo + Preposição + } \\
\text { Antropônimo }\end{array}$ & 24 & (Fazenda) Irara de Manuel Vidal \\
\hline Preposição + Substantivo + Adjetivo & 16 & (Fazenda) do Córrego Grande \\
\hline $\begin{array}{l}\text { Pronome de Tratamento + } \\
\text { Antropônimo }\end{array}$ & 15 & (Fazenda) Sr. Nivaldo Borges \\
\hline Antropônimo & 14 & (Fazenda) Antônio de Miranda \\
\hline Adjetivo + Substantivo & 10 & (Fazenda) Nova Jales \\
\hline Preposição + Antropônimo & (Fazenda) de Claudio R de Souza \\
\hline Adjetivo + Antropônimo + Numeral & 11 Ita I \\
\hline
\end{tabular}

Fonte: Elaboração própria

No Quadro 3, o nome próprio caracteriza os antropônimos. Em se tratando dos aspectos morfológicos dos antropônimos, Amaral e Seide (2020, p. 101) destacam que "em português, bem como em muitas outras línguas, não é possível diferenciar os nomes comuns dos nomes próprios por meio de marcas morfológicas. Assim, qualquer palavra 
ou sequência de palavras pode vir a ser um nome próprio". Ainda de acordo com os mesmos autores, "os limites para esta possibilidade, conforme Fernández Leborans (1999, p. 83), são pautados por convenções socioculturais e não propriamente pela gramática da língua (cf. também Bajo Pérez (2002, p. 45))" (AMARAL; SEIDE, 2020, p. 101).

No exame da formação dos topônimos compostos, foi considerada a base linguística dos formantes, obtendo-se os seguintes resultados: dentre os 1.243 topônimos examinados, 1.159 são de base portuguesa e 84 de línguas indígenas, estes últimos classificados como elementos específicos híbridos, sendo 57 formados por elementos linguísticos de língua portuguesa + língua indígena como ocorre em (Fazenda) Vale do Sucuri; (Fazenda) da Cabeceira do Irara; (Fazenda) Alto da Ariranha; e 27 de língua indígena + língua portuguesa - (Fazenda) Irara de Manuel Vidal; (Fazenda) Irara de José A. Macedo; (Fazenda) Tamandaré de Manuel Paula (Fazenda) Ariranha de João Chaves.

Na sequência, os topônimos compostos são analisados quanto ao grau de fixidez. Nesse particular, o exame dos dados demonstrou que os fraseotopônimos, a exemplo dos fraseologismos em geral, são passíveis de serem nivelados em graus distintos de fixidez, alguns deles apresentando grau de sequências cristalizadas (fixidez total), e outros com grau de fixação semi-cristalizada (fixidez parcial). Para tanto, foi retomado o modelo taxionômico proposto por Dick (1990) que teve como objetivo criar um padrão terminológico com base no conteúdo semântico do nome. Esse modelo é composto por 27 categorias. Para fins de exemplificação, foram selecionados fraseotopônimos pertencentes a duas taxionomias toponímicas: os hagiotopônimos e os antropotopônimos.

Os hagiotopônimos apresentam sequências cristalizadas, ou seja, fixidez total, como se pode observar em topônimos como (Fazenda) S. João Batista; (Chácara) Santa Rita de Cássia; (Sítio) São Sebastião; (Fazenda) Santa Ana; (Fazenda) Santa Cruz; (Fazenda) Santa Luzia; (Fazenda) Santa Maria; (Fazenda) Santa Madre Cabrine; (Fazenda) Santo Antônio da Serra; (Fazenda) São Bom Jesus; (Fazenda) São Francisco; (Fazenda) São João; (Fazenda) São Jorge; (Fazenda) São José dos Coqueiros; (Estância) São Judas Tadeu. Nota-se que os hagiotopônimos apresentam um grau de fixidez completo porque essa categoria de designativo resulta obrigatoriamente da associação entre dois formantes santo(a) + nome da entidade sagrada (Santo + Antônio), existindo, pois, entre os formantes um grau indissociável, permanente, imutável.

Já entre os antropotopônimos não se observa o mesmo grau de fixidez, pois o nível de soldadura entre os elementos desse tipo de sintagma é semi-cristalizado, o que permite que o topônimo seja mutável e deduzível a partir dos elementos (parcial e/ou total) ou por meio do contexto, isto é, com um grau de fixidez parcial, como acontece com os 
- | Fraseo(topônimos): um estudo de topônimos polilexicais na perspectiva da fraseologia

seguintes topônimos: (Fazenda) Maria Tereza; (Fazenda) Lázaro F. Dias; (Fazenda) Abel L. da Silva, de; (Fazenda) Antônio Alves, de; (Fazenda) Álvaro L. de Almeida; (Fazenda) Antônio de Miranda; (Fazenda) Antônio R. Garcia; (Fazenda) Arlindo Batista de Oliveira; (Fazenda) Edson Batista de Oliveira; (Fazenda) João F. de Souza; (Fazenda) José Nunes da Silva.

A forma semi-cristalizada também é acentuada em topônimos marcados pelo processo de toponimização, como se pode notar na relação dos elementos constituintes de topônimos como (Fazenda) Córrego do Ouro II; (Fazenda) da Cabeceira do Córrego da Água Vermelha; (Fazenda) Barra do Córrego do Buritizal; (Retiro) Fazenda Córrego da Porteirinha; (Fazenda) Fazenda Perdiz, da; (Fazenda) Cabeceira da Chácara; (Fazenda) Cabeceira do Córrego do Mato, da; (Fazenda) Córrego d'antas de Augusto Leal; (Retiro) Fazenda da Furna, da; (Fazenda) Lagoa do Araré, da. Nota-se que a elevação de um nome de acidente geográfico (elemento genérico do sintagma toponímico) à condição de topônimo (elemento específico do sintagma toponímico) gera a toponimização desse termo, o que pode modificar o sentido global do topônimo, tornando-o, menos fixo, ou até mesmo, não composicional. Por exemplo, em (Fazenda) da Fazenda Perdiz, se for excluído o primeiro elemento do termo específico (Fazenda da Perdiz), por ele já se configurar como termo genérico, o grau de fixação completo é afetado, gerando uma fixação parcial, que é denominada por Gross (1996) como sintagma semi-cristalizado.

Em síntese, pode-se reiterar que a amostra de fraseotopônimos estudados demonstrou a possibilidade de associação entre os estudos fraseológicos e os estudos toponímicos, levando em consideração a produtividade dos topônimos compostos no recorte investigado. Este estudo evidenciou ainda que analisar a estrutura do sintagma toponímico composto é também examinar as combinações sintagmáticas e os diferentes graus de fixidez e de soldadura existentes no âmbito dos topônimos compostos. O resultado das análises reitera, pois, a proposta de Marques (2017) de considerar o topônimo composto como um caso de soldadura entre os itens lexicais que integram os fraseologismos ou, neste caso, ofraseotopônimo.

\section{Algumas considerações finais}

Este artigo teve como objetivo discutir o conceito de fraseotopônimo com base na análise de uma amostra de topônimos compostos que nomeiam acidentes humanos da Microrregião de Paranaíba, Mesorregião Leste do Estado de Mato Grosso do Sul e que se configuram como sequências polilexicais cristalizadas, com o objetivo principal de analisar a estrutura morfológica dos designativos, considerando, sobretudo, a tendência de composição fraseológica desses topônimos. 
Os dados analisados conduzem para uma nova possibilidade de discussão da natureza de topônimos compostos com base em outro viés teórico, no caso, calcada em fundamentos teóricos da Fraseologia, que analisam os topônimos como uma unidade fraseológica. De modo geral, o corpus em que se baseia este estudo fornece uma amostra, em termos de nomeação de acidentes humanos rurais que evidenciam um número representativo de sequências polilexicais cristalizadas.

Retomando a perspectiva teórica de Gross (1996), uma sequência é dita cristalizada se ela evidencia uma fixidez total ou parcial de regras da combinatória sintagmática. Além disso, o autor estabelece uma escala que possibilita apurar o grau de fixidez (cristalização) por meio de sequências cristalizadas e semi-cristalizadas. Nota-se que o interesse de tal classificação é ajudar a mensurar a fixidez das sequências para explicar o fenômeno fraseológico e descrever o processo de cristalização.

Face ao exposto, neste trabalho buscou-se identificar o grau de fixação dos topônimos compostos analisados considerando que, a partir dos diferentes graus de fixidade, pode-se construir explicações para as manipulações a que os topônimos compostos se prestam, partindo do pressuposto de que a Fraseologia é um fenômeno que se exprime por meio de associações sintagmáticas recorrentes e da fixidez enquanto processo pelo qual essas associações se realizam. Nesse contexto, os dados analisados evidenciam que os fraseotopônimos são exemplos produtivos para distinguir graus de fixidez em topônimos polilexicais.

Em outras palavras, não se pode analisar uma unidade fraseológica considerando os seus itens isoladamente, mas sim a partir do conjunto dos dados como se fossem uma só estrutura de sentido global. Esse critério, seguido da polilexicalidade, é que dá norte e justifica o fato de as unidades aqui analisadas poderem ser consideradas fraseo(topônimos). Além disso, responde à pergunta formulada no início do texto: todo topônimo composto pode ser entendido como um fraseotopônimo? A resposta é positiva, desde que a formação toponímica seja composta por no mínimo dois itens lexicais indissociáveis, com fixidez completa ou parcial, gerando, assim, uma unidade de sentido único.

Em síntese, os dados confirmam a importância do estudo dos topônimos compostos segundo os parâmetros da Fraseologia, uma vez que a amostra analisada atende ao critério da polilexicalidade defendida por Gross (1996) e Mejri (1997). A análise dos dados confirma, enfim, que os fraseotopônimos possuem característica morfológica polilexical, indissociável e evidenciam graus distintos de cristalização ou fixação, sobretudo, em topônimos constituídos por uma combinação lexical metafórica e/ou classificações análogas referentes a contextos históricos, políticos, sociais e religiosos. 
- | Fraseo(topônimos): um estudo de topônimos polilexicais na perspectiva da fraseologia

Acresce-se, por fim, que este texto, dada a sua amplitude e os seus objetivos, não contemplou todos os enfoques teóricos possíveis acerca da Fraseologia e nem teve como intuito esgotar o assunto. A discussão apresentada é produto de uma interpretação do assunto à luz dos enfoques teóricos adotados e tem a expectativa de que, além de ter avançado no exame da temática, possa suscitar novas discussões acerca do conceito de fraseotopônimos, entendido como uma forma de aplicação dos fundamentos da Fraseologia ao estudo de nomes de lugares de estrutura polilexical.

\section{REFERÊNCIAS}

AMARAL, E. T. R.; SEIDE, M. S. Nomes próprios de pessoa: introdução à antroponímia brasileira. São Paulo: Blucher, 2020.

ATEMS - Atlas Toponímico de Mato Grosso do Sul. Sistema de Dados. Campo Grande: UFMS, 2018 (acesso restrito).

CARDOSO, L. Toponímia brasílica. Rio de Janeiro: Biblioteca do Exército Editora, 1961.

CORPAS PASTOR, G. Manual de fraseologia española. Madrid: Gredos, 1996.

DAUZAT, A. La Toponymie Française. Paris: Payot, 1946.

DAUZAT, A. Les noms de lieux: origine et évolution, villes et villages, pays, cours d'eau, montagnes, lieux-dits. Paris: Librairie Delagrave, 1947.

DICK, M. V. de P. A. A motivação toponímica e a realidade brasileira. São Paulo: Edições Arquivo do Estado, 1990.

DICK, M. V. de P. A. Toponímia e Antroponímia no Brasil. Coletânea de Estudos. São Paulo: Serviço de Artes Gráficas/FFLCH/USP, 1992.

DICK, M. V. de P. A. Os nomes como marcadores ideológicos. Acta Semiótica et Lingüística - SBPL (Sociedade Brasileira de Professores de Lingüística), São Paulo: Plêiade, v. 7, p. 97-122, 1998.

DUBOIS, J. et al. Dicionário de linguística. São Paulo: Cultrix, 1973. 
DRUMOND, C. Contribuição Bororo à toponímia brasílica. São Paulo: Editora da USP, 1965.

GROSS, G. Les expressions figées en français. Noms composés et autres locutions. Paris: Editions Ophrys, 1996.

ISQUERDO, A. N. La recherche toponymique au Brésil: une perspective historiographique. Cahiers de Lexicologie, Paris, ano 2, n. 101, p. 15-35, 2012.

MARQUES, E. A. Fraseotopônimos: estabelecendo diálogos entre a fraseologia e a toponímia. Revista Guavira, Três Lagoas, n. 25, p. 23-33, jul./dez. 2017. Disponível em: http://websensors.net.br/seer/index.php/guavira/article/view/589/435. Acesso em: 17 maio 2019.

MEJRI, S. Le figement lexical: descriptions linguistiques structuration sémantique. Tunis: Publications de La Faculté des Lettres, Université de La Manouba, 1997.

MEJRI, S. Introduction: Polysémie et polylexicalité. Syntaxique et Sémantique, Caen, n. 5, p. 13-30, 2004/1. Disponível em: https://www.cairn.info/revue-syntaxe-etsemantique-2004-1-page-13.htm. DOI: https://10.3917/ss.005.0013. Acesso em: 15 jun. 2018.

MEJRI, S. Figment absolu ou relatif: La notion de fegré de figement. Linx, Revue des linguistes de l'université Paris X Nanterre, Paris, n. 53, p. 183-196, 1 dez. 2005. Disponível em: http://journals.openedition.org/linx/283. DOI: https://10.4000/linx.283. Acesso em: 23 maio 2019.

MEJRI, S. Polylexicalité, monolexicalité et double articulation: la problématique du mot. Cahiers de Lexicologie, Paris, v. 2, n. 89, p. 209-221, 2006.

ORTíZ ALVAREZ, M. L. Expressões idiomáticas do português do Brasil e do espanhol de Cuba: estudo contrastivo e implicações para o ensino de português como língua estrangeira. 2000. Tese (Doutorado em Linguística) - Instituto de Estudos da Linguagem, Universidade Estadual de Campinas, Campinas. Disponível em: http://www. repositorio. unicamp.br/handle/REPOSIP/269747. Acesso em: 27 mar. 2019. 
- | Fraseo(topônimos): um estudo de topônimos polilexicais na perspectiva da fraseologia

PAMIES BERTRAN, A. A metáfora gramatical e as fronteiras (externas e internas) da fraseologia. Revista de Letras, Fortaleza, v. 1, n. 33, p. 51-77, jan./jun. 2014. Disponível em: http://www.periodicos.ufc.br/revletras/article/view/1492/1386. Acesso em: 27 maio 2019 .

PAMIES BERTRAN, A. Aux limites du limitrophes: à propos des catégories phraséologiques. In: SFAR, I.; BUVET, P.-A. (coord.). La phraséologie entre fixité et congruence. Louvain-la-Neuve: Academia l'Harmattan, 2018. p. 221-263.

SAMPAIO, T. O tupi na geografia nacional. Memoria lida no Instituto Historico e Geographico de S. Paulo. São Paulo: Typ. da Casa Eclectica, 1901. Disponível em: http://etnolinguistica.wdfiles.com/local--files/biblio\%3Asampaio-1901-tupi/ sampaio_1901_tupi.pdf. Acesso em: 26 jul. 2020.

SANTAMARÍA PÉREZ, M. I. Tratamiento de las unidades fraseológicas en la lexicografía bilingüe español-catalán. 2000. Tesis (Doctorado em Estudos Linguísticos) - Facultad Filosofía y Letras, Alicante, 2000. Disponível em: http://www.cervantesvirtual.com/nd/ ark:/59851/bmcj67d8. Acesso em: 20 maio 2019.

SAUSSURE, F. de. Curso de linguística geral. 28. ed. São Paulo: Cultrix, 2012.

TRISTÁ PÉREZ, A. M. Fuentes de las unidades fraseológicas. Sus modos de formación. In: CARNEADO MORÉ, Z. V.; TRISTÁ PÉREZ, A. M. Estudios de fraseología. La Habana: Academia de Ciencias de Cuba, 1984. p. 281-303.

XATARA, C. M.; RIOS, T. H. C. O estudo contrastivo dos idiomatismos: aspectos teóricos. Caderno Seminal Digital, Rio de Janeiro, v. 7, n. 7, p. 54-65, jan./jun. 2007. Disponível em: http://www.dialogarts.uerj.br/admin/arquivos_seminal/semina_VIII.pdf. Acesso em: 10 set. 2018. 
- | Fraseo(topônimos): um estudo de topônimos polilexicais na perspectiva da fraseologia

COMO CITAR ESTE ARTIGO: SILVA, Camila André do Nascimento da; ISQUERDO, Aparecida Negri. Fraseo(topônimos): um estudo de topônimos polilexicais na perspectiva da fraseologia. Revista do GEL, v. 17, n. 2, p. 286-308, 2020. Disponível em: https://revistadogel.gel.org.br/

DOI: http://dx.doi.org/10.21165/gel.v17i2.2450

Submetido em: 28/10/2019 | Aceito em: 20/06/2020. 